\title{
Discovering and Applying Mindfulness in English Language Teaching: A Book-Review
}

\author{
Correspondence: $\quad$ Luisito M. Nanquil $\quad$ Bulacan State University, Philippines \\ <luisito.nanquil@bulsu.edu.ph> \\ Crisanta T. De Leon \\ $<$ crisanta.deleon@bulsu.edu.ph> \\ Head of Faculty Development Program, Bulacan State University, \\ Philippines.
}

At the time when students and teachers are experiencing all the negative thoughts and emotions caused by transitions and changes which have come to their lives spontaneously, the power of mindful thinking plays an imperative role. One of the steps in promoting and maintaining social, and emotional well-being of people is to be connected. But a number of people do not know when and how to spark mindfulness and well-being to others. They think there are so many thoughts that linger on their minds and overload of those issues make them feel weary. As teachers handle several issues in the classroom and virtual world, their personal well-being which includes social, emotional, and mental being is pressed also. It is the intention of the reviewer to examine this widely circulated material that aims to inform or orient readers particularly professionals like teachers among others on how they can practice mindfulness to sustain and protect emotional and social well-being.

The book is entitled Mindfulness at Work and was written by Anna Black. The author started to embrace mindfulness as her way of managing general and work-related stress from corporate world. She has professional background in publishing which gives us the thought that for long she has encountered different levels of stress. She has taught mindfulness in the worksite and has been teaching stress reduction using mindfulness since 2006

Being an evaluator and reviewer of this material, I have my own thoughts and reflections. The tips from the mindfulness practice are more than useful and relevant in the field of teaching and language teaching. Teachers that we are, inevitable changes, pressure, and stress confront our lives.

In promoting the well-being of both teachers and students in the language classroom, a self-practice mindfulness plays a very important role. Through this book, those who can follow the procedures and steps can reduce stress, live in the moment and be more productive and satisfied at work. It is a practice that all educators have to apply and live so that they can carry out even difficult tasks while they handle and manage ESL classes.

The first Chapter is Living in the Moment. This chapter discusses the effects of stress to our life and work. From this point, mindfulness is unwrapped and being introduced as a powerful tool to combat and deal with stressful situations. When we say 'mindfulness' we refer to the process of paying attention to your experience as it comes out without judgment. Further, this part highlights mindfulness as a representation of our experience that carries thoughts, physical sensations, and emotions. Not to forget that this part includes the possible and tangible benefits we could get from mindfulness.

Chapter second is You at Work. In this chapter, the simple and basic steps of doing mindfulness are being applied so as to feel the benefits and impact on our lives. It underscores the value of curiosity as an initial step towards embracing the attitude of mindfulness. Paying attention to what is happening now and accepting your strengths, weaknesses are some of the steps that can help you achieve mindfulness. Making friends with others while paying attention to our thoughts is promoted by mindfulness attitude.

Chapter three holds and explains You and Others at Work. This chapter illustrates clearly how work is necessary and valuable when we deal with others. It is indicated in this part that work is about relationships. From this area, people are interconnected with colleagues, customers, clients, service providers, students, and suppliers. When we are aware of our relationships with others, we can provide and do better in our services and transactions. The value and place of listening is also stressed in this chapter. As communicators and professionals, we need to be sensitive and careful on our utterances. The importance of 'listening' is also underscored here. Other salient elements such as attention, intention, attitude, and communication are expounded in details for readers to apply and ponder.

The last Chapter is At Home. This part talks about the role of mindfulness at home as we try to lessen or reduce the stress and negativities we catch outside. By using mindfulness, we can become cautious of the role each of us play that contribute to our well-being. The attention we possess is a powerful tool and through mindfulness we can learn to adjust it more wisely both at work and at home. The convenience and peace we have it home can be maintained by the mindfulness practice. In this chapter, it is indicated that mindfulness does not limit its benefits to us who practice it but we can also help others specially our students and colleagues to promote health well-being. In the disruptive time, when almost all classes and transactions are being done at home, mindful practice can help us and our students to stay relaxed, focused, and aware of our responsibilities and duties.

After identifying the points, issues, and concepts of the book, the reviewer highly recommends it. There are plenty of benefits language teachers and other specialists/professions can get from the book. If language teachers have the knowledge on the practices and principles of mindfulness, definitely they are aware of the emotions, barriers, and constraints that ESL students are facing both in online and offline classes. The identification of needs, challenges, and problems in the learning process can aid the language teacher to promote health, social, and emotional well-being of the students. Mindfulness techniques applied to linguistics and language instruction can definitely lift and promote quality education whatever the modalities are. Through incorporation of mindfulness, the language teacher and other workers can establish and create healthy learning atmosphere away from stress, anxiety, and fear. It somehow connects to an old adage in education known to the world as no child is left behind. 
As a reviewer, my constructive suggestion on the book is to include a chapter where specific lesson or learning plans are available for the utility and perusal of future readers and researchers.

This book with its enticing and relevant concepts and insights should be read and infused by language teachers and all teachers for that matter. The ideas and theories are essential to the practice of language teaching and applied linguistics. During the time of struggle and stress, when some people feel low and downhearted, mindfulness attitude and technique can guide and uplift their well-being.

\section{Bio-notes}

Dr. Luisito Nanquil is a faculty of the College of Arts and Letters and Graduate Division of Bulacan State University where he is handling language and literature courses. His research interests are TESOL, curriculum design, cultural studies, and sociolinguistics.

Dr. Crisanta de Leon is serving as the Head of Faculty Development Program of Bulacan State University, where she is also handling language and literature courses. Her research interests are multilingual education and intercultural communication.

\section{Reference}

Black, A. (2014). Mindfulness at work. CICO Books. 